\title{
Spectrum Sensing \& Channel state estimation for cognitive radio using Pointing Vector Theorem
}

\author{
Amit Talreja ${ }^{1}$, Professor Prabhat Patel ${ }^{2}$ \\ Student ME in Communication System, Jabalpur Engineering College, Jabalpur, India ${ }^{1}$ \\ HOD, Electronics and Communication, Jabalpur Engineering College, Jabalpur, India ${ }^{2}$
}

\begin{abstract}
This report present an overview of cognitive radio and cognitive radio network. The report list enabling technique for cognitive radio and describe the state-of-art in cognitive radio standards, regulation, product and research. The availability of spectrum holes, i.e., frequency band assigned to a primary user but that are vacant in a given place at a given time, can be estimated with spectrum sensing technique, such as energy detection $\&$ feature detection. When little or no knowledge of the primary user signal is available, energy detection is useful while feature detection can exploit a priori information about the used waveforms. We have studied the performance of an energy detection scheme in terms of probability of detection and probability of false alarm without and with cooperation between the nodes. Cooperative detection by combining the observation of several cognitive radio node can be used to improve the performance of spectrum sensing. The result include both analysis and computer simulation using Matlab.
\end{abstract}

Keyword: Poynting Vector, Cognitive Radio, Spectrum Sensing \& Channel state estimation

\section{INTRODUCTION}

Knowledge of the channel state is required at the receiver for coherent reception. Thus, the channel state has to be estimated in the receiver. In addition, the computation of the channel capacity of a cognitive radio link and the power control algorithm in the transmitter require knowledge of channel-state information. This implies that digital baseband algorithm for adaptive estimation of the state of a fast fading channel are also needed in CR system. Channel identification algorithm can be classified into three categories: data-aided, non-data aided and decision-directed methods. Data-aided channel estimation method assume that the transmitted data is known and use this information in deriving the channel estimates. Nondata aided channel estimation method assume unknown transmitted data and remove the data by averaging. Decision-directed method approximate the data-aided method by detecting the data and using this data as a reference signal to the estimator.

\subsection{Active spectrum sensing technique}

In the spectrum has been classified into three type by estimating the incoming RF stimuli, thus, black spaces, grey space and white spaces. Black space are occupied by high power local interferer some of the time and unlicensed user should avoid those space at those times. Grey space are partially occupied by low power interferer but they are still candidate for secondary use. White space are free RF interferer except for ambient noise made up of natural and artificial form of noise e.g. thermal noise, transient reflection and impulsive noise. White space are obvious candidate for secondary use.

The goal of the spectrum sensing is to decide between the two hypotheses, namely:-

$\mathrm{x}(\mathrm{t})= \begin{cases}n(t) & H o \\ \alpha * s(t) & H 1\end{cases}$ where $x(t)$ is the complex signal received by the cognitive radio, $s(t)$ is the transmitted signal of the primary user, $n(t)$ is the additive white Gaussian noise (AWGN) and $h$ is the complex amplitude gain of the ideal channel. The delay has not been taken into account. If the channel is not ideal, multiplication of $h$ and $s(t)$ will change to convolution. $H 0$ is a null hypothesis, which state that no licensed user is present in a certain spectrum band. $H 1$ is the alternative hypothesis which indicate that some primary user signal exists.

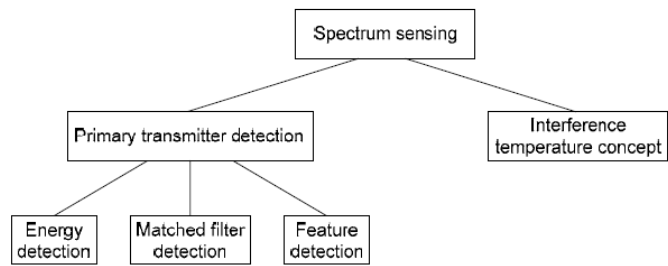

Figure 1: Spectrum sensing technique.

II. PERFORMANCE METRIC

The performance metric used for the simulation is receiver operating characteristic (ROC). It is completely specified by the value of probability of false alarm $P f$ and probability of detection $P \mathrm{~d}$. In signal detection theory, ROC is used for measuring the performance as a trade off between selectivity and sensitivity. The probability of detection (or true positive) $P \mathrm{~d}$ is given as a function the probability of false alarm (or false positive) $P f$.

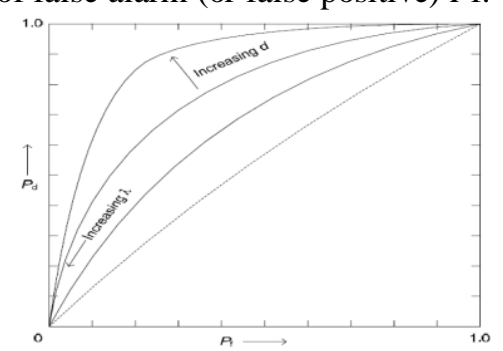

Figure: 2 An Example of ROC CURVE 
An example of a ROC curve is given. It can be seen from Now in Phasor form these equation may be written as the figure that by increasing the distance between the mean of the two densities $d$ the performance improves. If the threshold $\lambda=0$, the hypothesis $H 1$ is alway selected, thus, the probabilities $P \mathrm{~d}=P \mathrm{f}=1$. As the threshold $\lambda$ increases, $P \mathrm{~d}$ and $P$ f decrease. When the threshold $\lambda=\infty$, the hypothesis $H O$ is always selected and therefore $P \mathrm{~d}=P \mathrm{f}$ $=0$. The operating point and, thus, the probability of false alarm can be adjusted according to the application.

\section{LOCAL SPECTRUM SENSING BASED ON POYNTING VECTOR}

Consider a receiver model involving a linear time invariant filter with impulse response $\mathrm{h}(\mathrm{t})$. This filter will measure electric and magnetic component of signal corrupted by additive channel noise $\mathrm{n}(\mathrm{t})$ at an interval of $\mathrm{T}$ sec apart and is given as

$\mathrm{E}(\mathrm{t})=\mathrm{E}_{0}(\mathrm{t}) \mathrm{a}_{1}+\mathrm{n}(\mathrm{t})$

$\mathrm{M}(\mathrm{t})=\mathrm{M}_{0}(\mathrm{t}) \mathrm{a}_{2}+\{\mathrm{n}(\mathrm{t})+\Delta \mathrm{n}(\mathrm{t})\}$

Since $\mathrm{T}$ is very small neglecting $\Delta \mathrm{n}(\mathrm{t})$ will not cause major hindrance to the signal analysis, thus

$\mathrm{M}(\mathrm{t})=\mathrm{M}_{0}(\mathrm{t})+\mathrm{n}(\mathrm{t})$

Since instantaneous Electric Field can be in any direction assuming that direction to be $1^{\text {st }}$

$\mathrm{E}_{0}(\mathrm{t}) \mathrm{a}_{1}$

And instantaneous Magnetic Field is $90^{\circ}$ out of phase assuming that dimension to be in $2^{\text {nd }}$

$\mathrm{M}_{0}(\mathrm{t}) \mathrm{a}_{2}$

Now since white noise consist of infinite dimension, hence

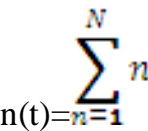

Since we have taken signal in 3 dimension $\{(\mathrm{x}, \mathrm{y}, \mathrm{z})$ or $(1,2,3)\}$ and for $\mathrm{N}$-dimensional Euclidean space their exist $\mathrm{N}$ component of noise $\mathrm{n}_{\mathrm{i}}(\mathrm{t})\{0 \leq \mathrm{j} \leq \mathrm{N}\}$, it can shown that out of these $\mathrm{N}$ component only 3 component of noise will affect the signal being transmitted and rest all can be ignored. Thus $\mathrm{n}(\mathrm{t})=\sum_{1}^{t} n_{\mathrm{n}}(\mathrm{t}) \mathrm{a}_{\mathrm{n}}$

OR

$\mathrm{n}(\mathrm{t})=\mathrm{n}_{1}(\mathrm{t}) \mathrm{a}_{1}+\mathrm{n}_{2}(\mathrm{t}) \mathrm{a}_{2}+\mathrm{n}_{3}(\mathrm{t}) \mathrm{a}_{3}$

From Poynting vector theorem, instantaneous Power is given by

$\widetilde{P}=\tilde{E}(\mathrm{t}) \times \widetilde{M}(\mathrm{t})$

$\mathrm{P}=\frac{1}{2}\left\{\left(\mathrm{E} 0(\mathrm{t}) \mathrm{M}^{*}{ }_{0}(\mathrm{t})\right) \mathrm{a}_{3}+\left(\mathrm{E}_{0}(\mathrm{t}) \mathrm{a}_{1} \mathrm{X} \mathrm{N} \mathrm{N}_{\mathrm{s}}(\mathrm{t})\right)-\left(\mathrm{N}_{\mathrm{s}}(\mathrm{t}) \mathrm{X} \mathrm{M}{ }_{0}(\mathrm{t})\right.\right.$

where $\widetilde{P}$ is the instantaneous flow in free space and Complex Poynting vector is given by

$\mathrm{P}=\frac{1}{2}\left(\mathrm{E}(\mathrm{t}) \mathrm{X}^{\mathrm{M}}(\mathrm{t})\right)$

From Maxwell's $1^{\text {st }}$ Equation for Time varying field

$\Delta \mathrm{X}^{\mathrm{M}}=d \mathrm{D} / \mathrm{dt}+\mathrm{\textrm {J }}=\boldsymbol{\varepsilon} \mathrm{E}_{d t}+\sigma \mathrm{E}$

But since conductivity is zero for free space, hence

$\Delta X^{M}=\varepsilon^{d E} / d t$

From Maxwell's $2^{\text {st }}$ Equation for Time varying field $\Delta \mathrm{XE}=-\mu^{d M} / d t$
$\Delta \mathrm{X} \mathrm{M}=\mathrm{j} \omega \varepsilon \mathrm{E}$

where $\omega$ is the frequency of operation

Or $\Delta X^{M} *=j \omega \varepsilon E^{*}$

And

$\Delta X E=-j \omega \mu M$

If we take Divergence of complex Poynting vector specified above that is

$\nabla . \mathrm{P}=\frac{1}{2} \nabla .(\mathrm{E} \mathrm{X} M *)=\frac{1}{2}\left(M * \nabla \times \mathrm{E}-\mathrm{E} . \nabla \mathrm{X}^{M} *\right)$

Now putting the value of $\Delta \mathrm{X} M *$ and $\Delta \mathrm{X} \mathrm{E}$ from equation (4) and (5) in above equation, we get

$\nabla . P=\frac{1}{2}\left(M *(-j \omega \mu \mathrm{H})-\right.$ E. $\left.\left(j \omega \mathbf{\varepsilon} \mathbf{E}^{*}\right)\right)$

Or $\nabla . P=\frac{1}{2}\left(-\mathrm{j} \omega \mu \mathrm{M} \mathrm{M}^{*}-\mathrm{j} \omega \varepsilon \mathrm{E} \mathbf{E}^{*}\right)$

Taking the volume integral of above written equation

$\iiint \nabla \cdot P \cdot d v=\frac{-j \omega \iiint(\mu \mathrm{M} \mathrm{M} *+\varepsilon \mathrm{E} \mathbf{E} *) \mathrm{d} v}{2}$

But by divergence theorem which states that you can transform a volume integral to a surface integral by applying a simple operation that is

$\oint P . d s=\iiint \Delta \cdot P \cdot d v$

Thus

$\oint P . d s=\frac{-j \omega \iiint(\mu \mathrm{M} \mathrm{M} *+\varepsilon \mathrm{E} \mathbf{E} *) \mathrm{d} v}{2}$

As from equation (1) and (2) we know that received electric and magnetic field are errorness and contaminated with noise. Thus

$\tilde{E}_{\mathrm{r}}=\mathrm{E}_{0}(\mathrm{t}) \mathrm{a}_{1}+\sum_{1}^{t} n_{\mathrm{n}}(\mathrm{t}) \mathrm{a}_{\mathrm{n}}$

Similarly

$\widetilde{M}_{\mathrm{r}}^{*}=\mathrm{M}_{0}(\mathrm{t}) \mathrm{a}_{2}+\sum_{1}^{t} n_{\mathrm{n}}(\mathrm{t})_{\mathrm{n}}(\mathrm{t}) \mathrm{a}_{\mathrm{n}}$

From equation (7) describing the complex pointing vector, which says

$\mathrm{P}=\frac{1}{2}\left(\mathrm{E}_{\mathrm{r}}(\mathrm{t}) X \tilde{M}_{\mathrm{r}}^{*}(\mathrm{t})\right)$

$\mathrm{P}=\frac{1}{2}\left\{\left(\mathrm{E}_{0}(\mathrm{t}) \mathrm{a}_{1}+\mathrm{N}_{\mathrm{s}}(\mathrm{t})\right) \mathbf{X}\left(\mathrm{M}^{*}{ }_{0}(\mathrm{t}) \mathrm{a}_{2}+\mathrm{N}_{\mathrm{s}}(\mathrm{t})\right\}\right.$

Where $\mathrm{N}_{\mathrm{s}}(\mathrm{t})=\sum_{1}^{t} n_{\mathrm{n}}(\mathrm{t}) \mathrm{a}_{\mathrm{n}}$

Thus

a2) $\left.+\mathrm{N}_{\mathrm{s}}(\mathrm{t}) X \mathrm{~N}_{\mathrm{s}}(\mathrm{t})\right\}$

From the vector law we know that cross product of two similar vector is zero.

Hence

$\mathrm{P}=\frac{1}{2}\left\{\mathrm{E}_{0}(\mathrm{t}) \mathrm{M}_{0} *(\mathrm{t}) \mathrm{a}_{3}+\left(\mathrm{E}_{0}(\mathrm{t}) \mathrm{a}_{1} \mathrm{X} \mathrm{N} \mathrm{N}_{\mathrm{s}}(\mathrm{t})\right)+\left(\mathrm{N}_{\mathrm{s}}(\mathrm{t}) \quad \mathrm{X}\right.\right.$ $\left.\left.\mathrm{H}_{0}(\mathrm{t}) \mathrm{a}_{2}\right)\right\}$

Now distributing the noise component and cross multiplying it with $\mathrm{a}_{1}$ and $\mathrm{a}_{2}$

OR

$\mathrm{a}_{1} X\left(\mathrm{n}_{1}(\mathrm{t}) \mathrm{a}_{1}+\mathrm{n}_{2}(\mathrm{t}) \mathrm{a}_{2}+\mathrm{n}_{3}(\mathrm{t}) \mathrm{a}_{3}\right)=\mathrm{n}_{2}(\mathrm{t}) \mathrm{a}_{3}-\mathrm{n}_{3}(\mathrm{t}) \mathrm{a}_{2}$ and 
International Journal of Advanced Research in Computer and Communication Engineering Vol. 3, Issue 10, October 2014

$\left(\mathrm{n}_{1}(\mathrm{t}) \mathrm{a}_{1}+\mathrm{n}_{2}(\mathrm{t}) \mathrm{a}_{2}+\mathrm{n}_{3}(\mathrm{t}) \mathrm{a}_{3}\right) X \mathrm{a}_{2}=\mathrm{n}_{1}(\mathrm{t}) \mathrm{a}_{3}+\mathrm{n}_{3}(\mathrm{t}) \mathrm{a}_{1}$

Now from equation (7) it is clear that Power transferred has no real component, hence

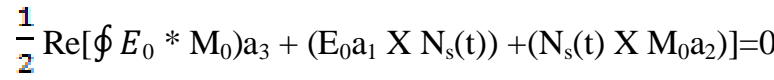
OR

$\frac{1}{2} \operatorname{Re}\left[\oint E_{0} * \mathrm{M}_{0}\right) \mathrm{a}_{3}+\oint E_{0} *\left(\mathrm{~N}_{2}(\mathrm{t}) \mathrm{a}_{3}-\mathrm{N}_{3}(\mathrm{t}) \mathrm{a}_{2}\right)+\oint M_{\mathrm{o}}$

$\left.*\left(\mathrm{~N}_{3}(\mathrm{t}) \mathrm{a}_{2}-\mathrm{N}_{1}(\mathrm{t}) \mathrm{a}_{3}\right)\right]=0$

OR

$E_{0} * M_{0} a_{3}=E_{0} * N_{2}(t) a_{3}-E_{0} N_{3}(t) a_{2}-M_{0} N_{1}(t) a_{3}+M_{0} N_{3}(t) a_{2}$

OR

$\mathrm{E}_{0} \mathrm{M}_{0} \mathrm{a}_{3}=\left\{\mathrm{E}_{0} \mathrm{~N}_{2}(\mathrm{t})-\mathrm{M}_{0} \mathrm{~N}_{1}(\mathrm{t})\right\} \mathrm{a}_{3}-\left\{\mathrm{M}_{0} \mathrm{~N}_{3}(\mathrm{t})-\mathrm{E}_{01} \mathrm{~N}_{3}(\mathrm{t})\right\} \mathrm{a}_{2}$

Equating component of $\mathrm{a}_{3}$ and $\mathrm{a}_{2}$ direction, we have

$\mathrm{E}_{0} \mathrm{M}_{0}=\left\{\left(\mathrm{E}_{0} \mathrm{~N}_{2}(\mathrm{t})-\mathrm{M}_{0} \mathrm{~N}_{1}(\mathrm{t})\right\}\right.$

and $\mathrm{M}_{0} \mathrm{~N}_{3}(\mathrm{t})-\mathrm{E}_{0} \mathrm{~N}_{3}(\mathrm{t})=0$

Also for free space $\frac{|E|}{|M|}=\sqrt{\frac{\mu}{\varepsilon}}=120 \pi$

Or $|\mathrm{M}|=|\mathrm{E}| / 120 \pi$

Putting this value of in equation (19a) and (19b) and taking its magnitude

$\left|\mathrm{E}_{0} \mathrm{E}_{0}\right| / 120 \pi=\left|\left(\mathrm{E}_{0} \mathrm{~N}_{2}(\mathrm{t})-\mathrm{E}_{0} \mathrm{~N}_{1}(\mathrm{t}) / 120 \pi\right)\right|$

Or

$\left|\mathrm{E}_{0}\right|=120 \pi *\left|\mathrm{~N}_{2}\right|+\left|\mathrm{N}_{1}\right|$

And

$\left|\mathrm{M}_{0}\right|=\left|\mathrm{N}_{2}\right|+\frac{1}{120 \pi}\left|\mathrm{N}_{1}\right|$

Thus

$\mathrm{E}_{\mathrm{r}}=\left[\left\{120 \pi *\left|\mathrm{~N}_{2}\right|+2\left|\mathrm{~N}_{1}\right|\right\} \mathrm{a}_{1}+\left|\mathrm{N}_{2}\right| \mathrm{a}_{2}\right]$

And

$\mathrm{M}_{\mathrm{r}}=\left[\left|\mathrm{N}_{1}\right| \mathrm{a}_{1}+\left\{2\left|\mathrm{~N}_{2}\right|+\left(\frac{1}{120 \pi}\right)\left|\mathrm{N}_{1}\right|\right\} \mathrm{a}_{2}\right]$

Thus

$\mathrm{P}_{\mathrm{r}}=\frac{1}{2}\left(\mathrm{E}_{\mathrm{r}} \mathrm{X} \mathrm{M}_{\mathrm{r}}\right)$ from equation $7^{\text {th }}$ we get

$\mathrm{P}_{\mathrm{r}}=\frac{1}{2}\left[\left\{120^{\pi} *\left|\mathrm{~N}_{2}\right|+2\left|\mathrm{~N}_{1}\right|\right\} \mathrm{a}_{1}+\left|\mathrm{N}_{2}\right| \mathrm{a}_{2}\right] \mathrm{X}\left[\left|\mathrm{N}_{1}\right| \mathrm{a}_{1}\right.$ $\left.+\left\{2\left|\mathrm{~N}_{2}\right|+\left(\frac{1}{120 \pi}\right)\left|\mathrm{N}_{1}\right|\right\} \mathrm{a}_{2}\right]$

$\mathrm{P}_{\mathrm{r}}=\frac{1}{2}\left\{\left(753.6 *\left|\mathrm{~N}_{2}\right|^{2}\right) \mathrm{a}_{3}+6 *\left|\mathrm{~N}_{1}\right|\left|\mathrm{N}_{2}\right| \mathrm{a}_{3}+0.005\left|\mathrm{~N}_{1}\right|^{2} \mathrm{a}_{3}\right\}$

Taking $\mathrm{N}_{2}=\mathrm{kN}_{1}$ and solving $\mathrm{P}_{\mathrm{r}}$

$\mathrm{P}_{\mathrm{r}}=\left(376.8 \mathrm{k}^{2}+6 \mathrm{k}+0.005\right)\left|\mathrm{N}_{1}\right|^{2}$

Similarly noise power can be given as

$\left|\mathrm{N}_{\mathrm{s}}\right|=\mathrm{N}_{1}^{2}+\mathrm{N}_{2}^{2}$

Thus SNR is given as $\left|\mathrm{P}_{\mathrm{r}} / \mathrm{E}\left[\mathrm{N}_{\mathrm{s}}^{2}\right]\right|={ }^{\mathrm{Pr}} / \mathrm{NS}$

$=\left(643.23 \mathrm{k}^{2}+3.41 \mathrm{k}+0.009\right)\left|\mathrm{N}_{1}\right|^{2} /\left(\mathrm{k}^{2}+1\right)\left|\mathrm{N}_{1}\right|^{2}$

$=\left(643.23 \mathrm{k}^{2}+3.41 \mathrm{k}+0.009\right) /\left(\mathrm{k}^{2}+1\right)--\cdot-\cdot-\cdot-\cdot--$

Similarly from equation (13) $\mathrm{N}_{3}(\mathrm{t})=0$ as Electric and Magnetic field component cannot be equal .Also at the start we have taken noise to be white gaussian type having PSD as $N o / 2$ we can plot the graph for detected noise $\mathrm{N}_{\mathrm{s}}=\mathrm{N}_{1} \mathrm{a}_{1}+\mathrm{N}_{2} \mathrm{a}_{2}+0$ vs SNR

\section{NUMERICAL ANALYSIS}

4.1 Probability of False Alarm

The probability distribution function of a random variable $X$ with $2 N$ degree of freedom is given by [12]

$\mathrm{f}_{\mathrm{x}}(\mathrm{x})=\frac{x^{N-1} e^{X / 2}}{2^{N} \Gamma(N)}$

where $\Gamma($.$) is the gamma function.$

$\Gamma(u)=\int_{0}^{\infty} a^{u-1} \mathrm{e}^{-\mathrm{t}} \mathrm{dt}$

Now for a given threshold $\lambda$ the probability of false alarm under hypothesis H0 (as defined in (1)) can be computed as

$P_{f}=\operatorname{Prob}\{\mathrm{X}>\lambda \mid \mathrm{H} 0\}=\int_{\lambda}^{\infty} f_{\mathrm{x}}(\mathrm{x}) \mathrm{dx}==\frac{x^{N-1} e^{X / 2}}{2^{N} \Gamma(N)} \mathrm{dx}$

Let $x=2 u$; so,

$\mathrm{P}_{\mathrm{f}}=\frac{1}{2^{N} \Gamma(N)} \int_{\lambda / 2}^{\infty} 2^{N-1} u^{N-1} e^{-u} \cdot 2 d u=\frac{1}{\Gamma(N)} \int_{\lambda / 2}^{\infty} u^{N-1} e^{-u} d u$

From the definition of incomplete gamma function $\Gamma(s, x)=\int_{x}^{\infty} t^{S-1} e^{-t} d t$

Hence, $\quad \mathrm{P}_{\mathrm{f}=} \frac{\Gamma(N, \lambda / 2)}{\Gamma(N)}$

\section{SIMULATION RESULT}

The ROC curve are obtained by theoretical distribution of the $\mathrm{H}_{0}$ and $\mathrm{H}_{1}$ hypothesis. The result generated as per simulation shows a close resemblance to the curve obtained from the equation (26) and (32). The ROC plot between Probability of miss v/s Probability of false alarm for a threshold SNR of $3 \mathrm{db}$ and $5 \mathrm{db}$ (for higher SNR the curve does not show any difference). Figure 1 show a theoretical v/s simulated curve (obtained by using proposed Pointing Vector approach) showing a close resemblance between the $5 \mathrm{db}$ curve using an already defined approach [12] and the pointing vector approach. Here the curve is inspected to classify the performance more closely.

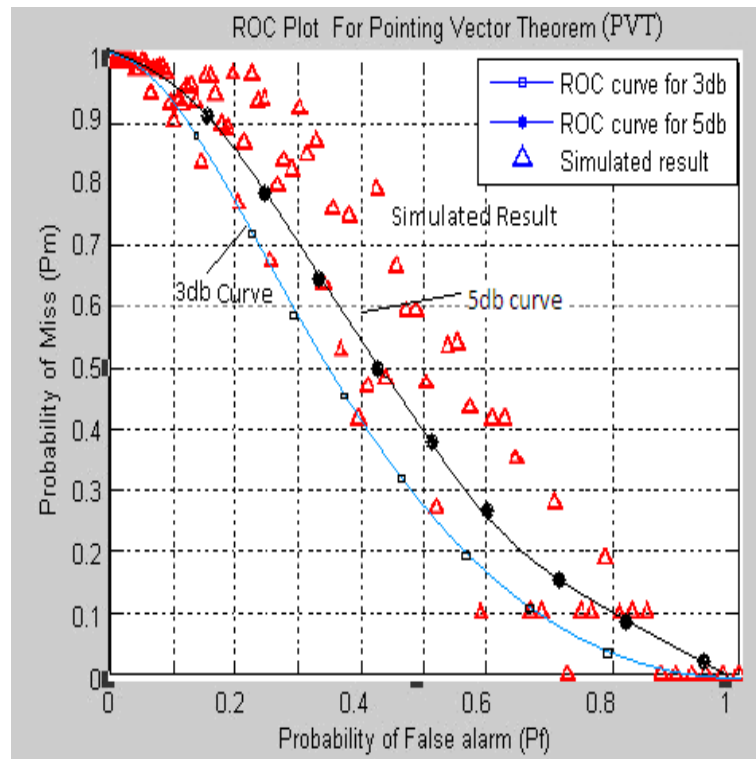

Fig: 1 Simulated and Theoretical ROC Curve for PVT 
International Journal of Advanced Research in Computer and Communication Engineering Vol. 3, Issue 10, October 2014

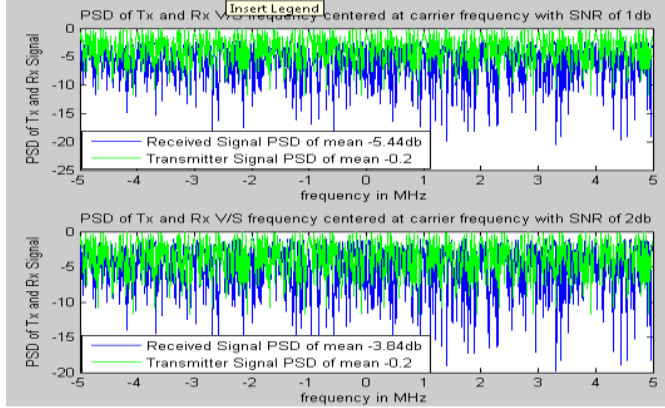

Figure 2(a): Power Spectrum Density v/s frequency in $\mathrm{MHz}$ for stated spectrum sensing under AWGN channel for an SNR of $1 \mathrm{dbm}$ and $2 \mathrm{dbm}$.

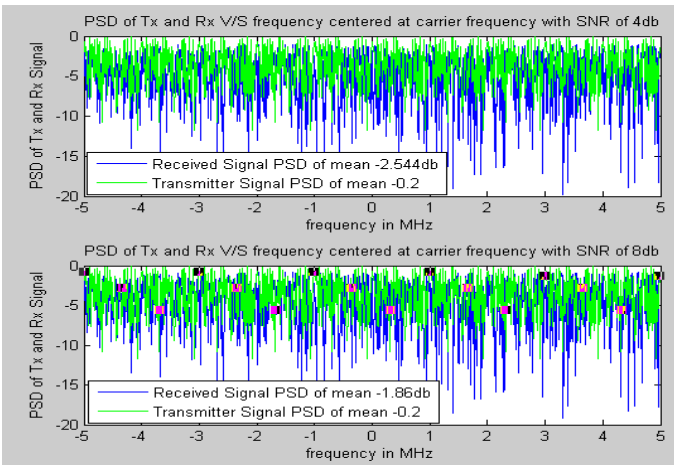

Figure 2(b): Power Spectrum Density v/s frequency in $\mathrm{MHz}$ for stated spectrum sensing under AWGN channel for an SNR of 4dbm and 8dbm.

Figure 2 show the Power spectral density at a mean SNR of $Y=-1 \mathrm{dbm},-2 \mathrm{dbm},-4 \mathrm{dbm},-8 \mathrm{dbm}$ and the local detection is made with energy detection after observing the signal for 1000 samples.

Figure 3 is for Probability of Miss v/s SNR in fading due to 3 kind of channel for $P_{f}=10^{-1}$ and one is the simulated curve for proposed method which show a close resemblence to the AWGN channel

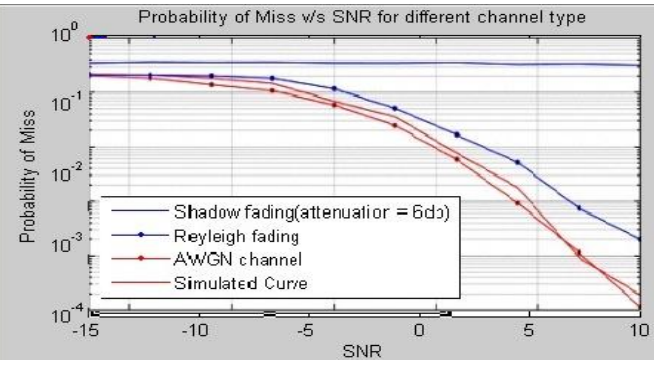

Figure 3: Probability of Miss v/s SNR in fading due to 3 kind of channel for $P_{f}=10^{-1}$ and No. of user $=1000$

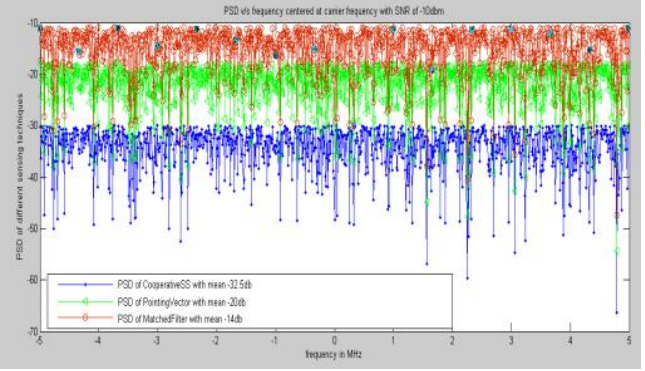

Figure 4: show PSD of the received signal for 3 different spectrum sensing method.
Also as it is clear from figure 4 showing the PSD of the Received signal power strength showing that received signal strength is best for Matched filter after which Poynting vector theorem can play a dominant role in spectrum sensing. But as we know that Matched filter technique require the shape of the signal to be known but in this method the prior knowledge about the shape is not compulsory. Below we have given some advantage and disadvantage of Matched filtering technique:

- Advantage of matched filter is that it need less time to achieve high processing gain and probability of false alarm and missed detection due to coherent detection [13].

- Disadvantage of matched filter is that it would require a dedicated sensing receiver for all primary user signal types.

- It requires the prior information of primary user signal which is very difficult to be available at the CRs.

At last figure 4 show probability of miss v/s SNR for different kinds of Channel is shown in figure. Figure shows 3 kinds of channel carrying the signal out of which AWGN shows the best graph in term of probability of miss v/s SNR.

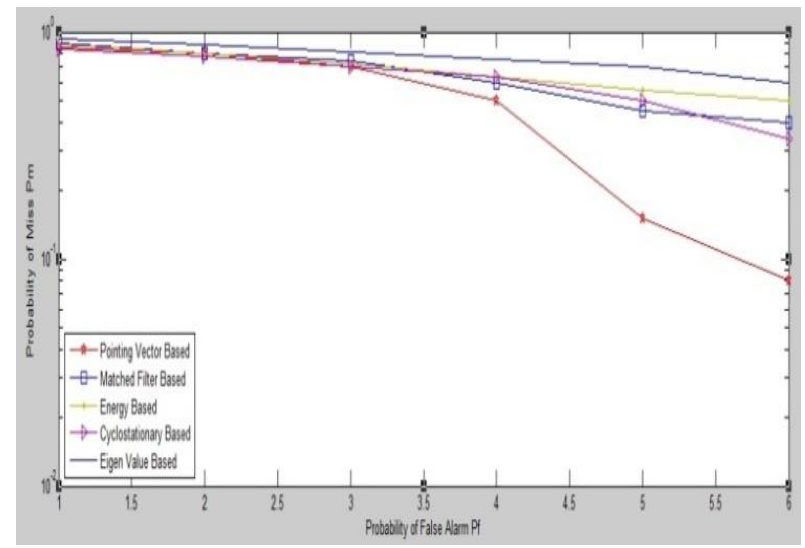

Figure 5: Probability of Miss v/s SNR for Different Spectrum Sensing technique

5.1 Detection over Rayleigh Fading Channel:

When the channel is varying because of fading effects, previously given equation on probability of detection will no longer hold true but does vary and is given by-

$\mathrm{P}_{\mathrm{d}, \text { fading }}=\int Q m(\sqrt{2 m \gamma}, \sqrt{\varepsilon})_{\mathrm{f}_{\mathrm{y}}(\mathrm{x}) \mathrm{dx}}$

where is the probability of distribution function of SNR under fading

Under Rayleigh fading, the signal amplitude follow a Rayleigh distribution. In this case, the SNR follow an exponential PDF,

$\mathrm{f}(Y)=\stackrel{1}{\overline{\bar{V}}} \exp \left(-\frac{Y}{\bar{V}}\right)$

Hence simulation of Rayleigh distribution is given at the end. Where as two plot are given below one showing magnitute response of Rayleigh Fading Channel and other showing the PDF simulated and theoretical Rayleigh PDF. 
International Journal of Advanced Research in Computer and Communication Engineering Vol. 3, Issue 10, October 2014

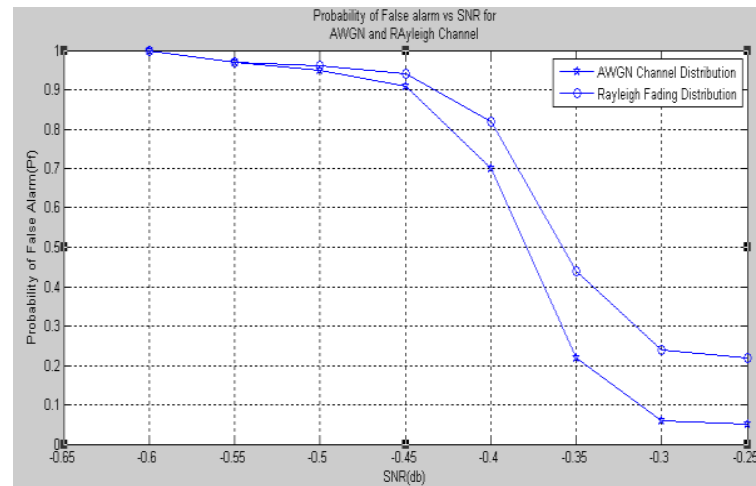

Figure 5: Shows the probability of false alarm v/s SNR for AWGN channel and Rayleigh fading Channel

\section{CONCLUSION}

Spectrum is a scarce resource and it has been a major focus of research over the last several decades. Cognitive radio technology, which is a one of the promising approaches to utilize radio spectrum efficiently, has become an attractive option. Deployment of cognitive radio network mainly depend on the ability of cognitive devices to detect licensed or primary users accurately and hence minimize interference to the licensed users. Spectrum sensing has been identified as a key functionality of a cognitive radio.

In this paper Numerical Analysis for Spectrum Sensing based on Poynting vector has been done, which give us the relation between electric field and noise. Hence if know the value of transmitted power you can calculate the values of noise component. Thus this method could be proved quite efficient while estimating the power transmitted. 